\title{
A EDUCAÇÃO INTERGERACIONAL FACE AO DISCURSO POLÍTICO DO ENVELHECIMENTO ATIVO
}

\author{
INTERGENERATIONAL EDUCATION IN FACE OF THE POLICY DISCOURSE OF \\ ACTIVE AGEING
}

\author{
Dernando Ilídio Ferreira \\ Doutor em Estudos da Criança pela Universidade do Minho (UMinho) \\ Universidade do Minho, Braga - Portugal. \\ filidio@ie.uminho.pt
}

\begin{abstract}
Resumo: Tal como outros termos formados com o sufixo "ismo", como racismo, sexismo, entre outros, o termo idadismo pretende dar conta de diversas formas de discriminação baseadas na idade das pessoas. Embora abranja também crianças e jovens, devido a diversas crenças, como por exemplo de que são imaturos e sem voz no espaço público, o idadismo afeta, hoje, especialmente, as pessoas idosas. Nas últimas décadas, tornou-se uma das principais formas de discriminação nas nossas sociedades, pelo que se pretende analisar criticamente este fenómeno, com base na literatura científica e na análise documental e recorrendo ainda a exemplos de programas intergeracionais. Situando a análise no contexto das políticas designadas de "envelhecimento ativo", difundidas sobretudo por instituições da União Europeia, este artigo discute a dimensão retórica e ideológica das mesmas, assim como a sua ótica economicista e produtivista. Em contraste com o discurso político e normativamente difundido do "envelhecimento ativo" e da "solidariedade intergeracional", defende-se uma educação intergeracional crítica capaz de promover e produzir a cidadania intergeracional. Pretende-se, deste modo, questionar a crescente institucionalização das pessoas idosas, e também de crianças e jovens, de modo a contribuir para o fortalecimento do espaço público da educação, pela via da experiência democrática e convivial.
\end{abstract}

Palavras-chave: Envelhecimento ativo. Idadismo. Cidadania. Educação intergeracional.

Abstract: Like other terms formed with the suffix "ism", such as racism, sexism, among others, the term idadismo intends to account for diverse forms of discrimination based on stereotypes and prejudices against individuals or groups based on age. Although it also covers children and young people, due to various beliefs, such as that they are immature and voiceless in public space, age affects, today, especially older people. In recent decades, it has become one of the main forms of discrimination in our societies, and it is therefore intended to critically analyse this phenomenon on the basis of scientific literature and document analysis using as well as examples of intergenerational programmes. Placing the analysis in the context of the so called "active aging policies", spread mainly by institutions of the European Union, this article discusses the rhetorical and ideological dimension of them, as well as their economic and productivist perspective. In contrast to the political and normatively widespread discourse of "active aging" and "intergenerational solidarity", it advocates a critical intergenerational education capable of promoting and producing intergenerational citizenship. In this way, it is intended to question the increasing institutionalization of the elderly, and also of children and young people, in order to contribute to the strengthening of the public space of education, through democratic and convivial experience.

keywords: Active ageing. Ageism. Citizenship. Intergenerational education.

\section{Para citar - (ABNT NBR 6023:2018)}

FERREIRA, Fernando Ilídio. A educação intergeracional face ao discurso político do envelhecimento ativo. Eccos - Revista Científica, São Paulo, n. 56, p. 1-21, e12820, jan./mar. 2021. Disponível em: https://doi.org/10.5585/eccos.n56.12820. 


\section{Introdução}

O envelhecimento demográfico representa uma das transformações sociais mais significativas do século XXI. A população global aumentou drasticamente desde o início do século XX, registando-se 1.5 milhão de pessoas, em 1900, 2.53 milhões, em 1950 e 7,8 bilhões, em 2020. Na Europa, apesar de ter ocorrido nas últimas décadas uma diminuição gradual da taxa de crescimento, a população aumentou, entre 1960 e 2020, de 354,5 para 447,7 milhões. Não é o único continente com uma população em envelhecimento, mas é na Europa que o fenómeno tem avançado mais. A nível mundial, 26\% da população têm atualmente menos de 15 anos e 9,3\% têm 65 anos ou mais, prevendo-se que atinja 16,0\% em 2050. Na Europa, as diferenças são maiores. O rácio entre pessoas com 65 anos ou mais e pessoas com idades no intervalo de 20 a 64 anos aumentou de 29\%, em 2010, para 34\% em 2019. Entre 0 e 14 anos são 15,2\%, entre 15 e 64 anos são 64,6 \% e com 65 anos ou mais são 20,3 \% (UNITED NATIONS, 2020; EUROPEAN PARLIEMENT, 2020).

Boa parte do discurso político, tanto em nível europeu como global, tem usado um tom economicista, e muitas vezes assustador, quando se refere ao envelhecimento demográfico, relacionando-o, sobretudo, com a dificuldade de sustentar os sistemas de saúde e de proteção social. Numa perspetiva crítica, saliento neste artigo a perspetiva normativista e produtivista desse discurso, particularmente, do "envelhecimento ativo" e da sua vinculação à questão intergeracional. Em relação ao discurso da "solidariedade entre gerações", destaco, por um lado, o seu papel de legitimação das políticas de pendor económico do "envelhecimento ativo" e, por outro lado, um conjunto de abordagens focadas nas relações intergeracionais, mas com enfoque numa educação intergeracional crítica e promotora de cidadania intergeracional. Nesse sentido, começo por analisar um fenómeno emergente, essencialmente desde a segunda metade do século XX, que dá pelo nome de "idadismo", em inglês ageism, o qual nos obriga a repensar tanto as políticas de envelhecimento como as políticas e as práticas intergeracionais.

\section{A discriminação baseada na idade: o idadismo}

$\mathrm{O}$ idadismo refere-se a atitudes e práticas negativas generalizadas em relação às pessoas, com base numa característica apenas - a sua idade. Essas atitudes e práticas podem ter como alvo diferentes grupos etários e não só pessoas idosas, mas é sobretudo em relação a estas que elas se manifestam, através de crenças e estereótipos, preconceito e atos efetivos de 
discriminação. A origem do termo idadismo é atribuída a Robert Butler, quando o usou, em 1969, numa entrevista ao Washington Post publicada com o título "Temores de raça e idade vistos na oposição habitacional". O jornal descrevia a apreensão de proprietários de imóveis em Chevy Chase, Maryland, um afluente subúrbio de Washington, DC, que ficaram preocupados com a decisão do National Capital Housing Authority (NCHA) de transformar um complexo de apartamentos em habitação pública. Ocorreram então manifestações hostis ao projeto, que tinha como objetivo fornecer residências para os idosos pobres, incluindo afroamericanos. Perante essas reações, à primeira vista inexplicáveis, já que os futuros residentes não representavam qualquer tipo de ameaça à localidade, Butler (1969) refletiu sobre os motivos e compreendeu que a construção deste tipo de empreendimento imobiliário naquele local era vista como um fator de desvalorização dos imóveis e de desprestígio dos residentes. Butler conta que durante a entrevista ao Washington Post lhe tinham perguntado se tais reações eram sinal de racismo, ao que ele respondeu: não é racismo, é “ageism”.

Tal como outros termos formados com o sufixo "ismo" - racismo, sexismo, etc.- o termo idadismo surgiu para dar conta de um novo tipo de discriminação negativa baseado na idade das pessoas. A discriminação negativa consiste na negação de um benefício ou direito a algo, com base na classificação de uma pessoa como membro de uma categoria social que, neste caso, é de natureza geracional. As expressões idadistas em relação às pessoas mais velhas têm, essencialmente três componentes: estereótipo, preconceito e discriminação (MARQUES, 2011): i) crenças e estereótipos vários fazem com que as pessoas de uma determinada idade sejam vistas como um grupo homogéneo, ao qual são associados traços negativos como a incapacidade e a doença. O preconceito consiste na expressão de sentimentos de desdém em relação ao envelhecimento e às pessoas mais velhas. Embora, de um modo geral, as pessoas não manifestem, de forma explícita e hostil, sentimentos negativos, estes têm frequentemente um caráter subtil, benevolente e paternalista. A discriminação manifesta-se em comportamentos e atos efetivos, podendo chegar à violência e aos maus tratos contra pessoas idosas.

O "vírus do idadismo" (PALMORE; WHITTINGTON; KUNKEL, 2009) contagia a maioria das pessoas em praticamente todos os países do mundo ao ponto de as próprias pessoas idosas internalizarem estereótipos negativos de que são fracas, doentes ou senis, com implicações na sua autoestima, saúde e bem-estar. Esses estereótipos contribuem para a discriminação generalizada contra pessoas idosas em diversos contextos, designadamente, no 
emprego, na assistência médica, nas famílias e nos serviços e instituições de acolhimento. $\mathrm{O}$ idadismo não pode ser encarado apenas como uma atitude negativa, individualizada, em relação às pessoas idosas. Este fenómeno tem causas e implicações ao nível do Estado e da sociedade, espelhando os nossos valores culturais mais profundos e as práticas institucionais da nossa sociedade (MARQUES, 2011).

Estudos do EURAGE (European Research Group on Attitudes to Age), nomeadamente o "The European Social Survey, 1999 (ABRAMS; RUSSELL; VAUCLAIR; SWIFT, 2011), mostram que as atitudes em relação ao envelhecimento e ao preconceito etário diferem entre países e culturas, porém, de um modo geral, os estereótipos identificados expressam mais a benevolência do que o reconhecimento de competência em relação às pessoas idosas. $\mathrm{O}$ preconceito e a discriminação em relação às pessoas mais velhas tendem a ser expressos subtilmente através de estereótipos ostensivamente "benevolentes". Muitas vezes, os idosos são vistos como simpáticos, respeitosos e com elevados padrões morais, podendo ser alvo de atitudes quer de admiração quer de pena. Por outro lado, ao incidir sobre aspetos como a economia, o emprego, o estatuto social, a amizade, entre outros, os resultados dos referidos estudos do EURAGE, os idosos são encarados como uma ameaça económica, maioritariamente por parte dos jovens, considerando que a sua contribuição para a economia é baixa e são elevados os custos que acarretam para os serviços de saúde. Acresce, ainda, uma ideia crescentemente generalizada de que a ocupação de postos de trabalho por pessoas mais velhas diminui a possibilidade de os jovens obterem emprego. Nos países europeus, a perceção de ameaça económica tem sido parcialmente mitigada através do aumento da idade de reforma, sendo assim as pessoas idosas vistas como economicamente ativas durante mais tempo; no entanto, devido ao aumento da concorrência por empregos, especialmente num cenário, como o que enfrentamos, caraterizado por elevadas taxas de desemprego jovem, as relações entre as gerações podem resvalar mais para o conflito do que para a solidariedade intergeracional. No contexto das políticas ditas de "envelhecimento ativo", a idade de reforma tem aumentado, sendo por isso cada vez mais necessário ter em conta esse tipo de perceções, pois tendem a gerar a crença de que é menos aceitável uma pessoa mais velha ocupar uma posição de elevado estatuto no contexto de trabalho. No que concerne às amizades, esses estudos mostram que elas se restringem a pessoas dentro da sua própria faixa etária. Por exemplo, $80 \%$ dos jovens entre os 15 e os 24 anos afirmam que não têm amigos com idades acima de 70 anos e $70 \%$ das pessoas com mais de 75 anos referem que não têm amigos com menos de 30 anos. 
Portanto, o idadismo não está necessariamente associado a atitudes agressivas e violentas, as quais podem ocorrer dentro de quaisquer faixas etárias e contextos sociais; o idadismo manifesta-se, sobretudo, em atitudes e práticas discriminatórias que estão de tal modo embutidas no modo como vemos o mundo e as relações sociais que nem sempre estamos conscientes da sua existência e das suas diferentes manifestações (MARQUES, 2011). O idadismo é fruto da categorização etária, que e é uma das mais enraizadas, cultural e estruturalmente, nas nossas sociedades. Ao longo do século XX, o uso da idade para determinar em que atividades participam ou não participam os indivíduos, que Kohli (1988) designa como "cronologização" da vida, consolidou-se a tal ponto que o Estado, as organizações do trabalho, as escolas, entre outras organizações e instituições sociais, passaram a assumir como natural, e não como um fenómeno socialmente construído, o uso da idade como critério para determinar quem foi qualificado ou desqualificado para participar em determinados programas e atividades.

\section{O envelhecimento ativo no discurso político: um dever ou um direito?}

Apesar de frequentemente reduzido ao fator cronológico, há um crescente reconhecimento de que o processo de envelhecimento deve ser entendido como uma acumulação de processos não apenas biológicos e psicológicos, nem de história de vida e de circunstâncias presentes, mas também das atitudes, expectativas, preconceitos e ideais das sociedades e culturas em que as pessoas se desenvolvem e envelhecem (COLEMAN; O'HANLON, 2004). No entanto, a ideia de que as pessoas mais velhas representam um fardo para as famílias, a sociedade e o Estado tem aumentado. As várias e crescentes formas de preconceito, discriminação e segregação relacionadas à idade tendem a ser interpretadas como sinais de fragilização dos laços tradicionais da solidariedade entre as diferentes gerações e é em grande medida nesse sentido que têm surgido, nas últimas décadas, políticas, programas e práticas visando promover a intergeracionalidade. O discurso político do envelhecimento ativo inclui as relações entre gerações como um dos seus princípios básicos, porém, é necessário conhecer e distinguir diferentes perspetivas e abordagens, provenientes, sobretudo, da investigação realizada no campo ainda emergente dos estudos intergeracionais.

Estamos perante questões complexas e controversas que desafiam as políticas e as práticas e também a investigação. Da parte da União Europeia, o discurso dominante tem sido o do "envelhecimento ativo", embora acompanhado, por vezes, do termo aditivo "saudável". 
Em 2010, a Comissão Europeia propôs que 2012 fosse considerado o "Ano Europeu do Envelhecimento Ativo", tendo depois introduzindo uma nuance denominando-o "Ano Europeu do Envelhecimento Ativo e da Solidariedade entre Gerações" (EUROPEAN PARLIAMENT; COUNCIL OF THE EUROPEAN UNION, 2011). Não é também de estranhar o facto de as Nações Unidas terem proclamado a atual década (2021-2030) como "a década do envelhecimento saudável", na linha de um conjunto de políticas e programas desenvolvidos nos últimos anos pela OMS (WHO, 2002, 2012, 2017, 2020). A hipótese de discussão que avanço neste artigo é a de que a nova designação - envelhecimento ativo e solidariedade entre gerações -, assim como o uso do qualificativo "saudável" têm contribuído para amenizar a natureza essencialmente económico-financeira do discurso do "envelhecimento ativo", centrado em questões do trabalho e do emprego, da idade da reforma, da sustentabilidade dos sistemas de proteção e segurança social, entre outras. Tratando-se de questões intrinsecamente relacionadas com os direitos humanos, o novo cenário demográfico do envelhecimento da população não pode ser visto como uma ameaça à solidariedade intergeracional, mas antes como uma mudança necessária das formas como a solidariedade intergeracional é praticada (DAATLAND; LOWENSTEIN, 2005, BENGTSON; OYAMA, 2007, SÁNCHEZ; KAPLAN; SÁEZ, 2010).

Desde finais da década de 1990 e, mais claramente já no presente século, a OMS e instituições da União Europeia têm utilizado e difundido o conceito de "envelhecimento ativo" como o cerne das políticas e programas de promoção da "solidariedade entre gerações", pondo a tónica na responsabilidade, não do tipo societal, mas eminentemente individual (COMISSÃO EUROPEIA, 2021). De um modo geral, as instituições europeias e outras à escala mundial adotaram o conceito de "envelhecimento ativo" nos termos em que ele foi apresentado na Segunda Assembleia Mundial das Nações Unidas sobre o Envelhecimento, que teve lugar em Madrid, em abril de 2002 (WHO, 2002). O Plano de Ação Internacional de Madrid sobre o Envelhecimento, no qual está incluída a intenção de aumentar o tempo de permanência no mercado de trabalho, pela via do aumento da idade da reforma, tornou-se um quadro orientador de políticas e práticas relacionadas com o "envelhecimento ativo".

Na perspetiva do Conselho da União Europeia, o envelhecimento ativo significa criar oportunidades para permanecer por mais tempo no mercado de trabalho, contribuindo para a sociedade através do trabalho não remunerado, nomeadamente através do voluntariado na comunidade e nas suas famílias ou transmitindo as suas habilidades às pessoas mais jovens 
(COUNCIL OF THE EUROPEAN UNION, 2010). Para a OMS, “manter a autonomia e a independência à medida que se envelhece é um objectivo-chave tanto para os indivíduos como para os decisores políticos" (WHO, 2002: 12). A autonomia é definida como "a capacidade percebida para controlar, lidar e tomar decisões pessoais sobre como se vive no dia a dia, de acordo com as próprias regras e preferências" e a independência como a "capacidade de viver independentemente na comunidade, com nenhuma ou pouca ajuda dos outros (WHO, 2002, p. 13).

Estas ideias têm sido disseminadas às escalas global, nacional e local, conquistando adeptos sobretudo entre instituições e profissionais que atuam nessa linha, mas escapando, em grande medida, ao escrutínio da análise sociológica crítica. Por parte dos apologistas do discurso político do "envelhecimento ativo", qualificativos como "ativo", "saudável", "produtivo" e "bem-sucedido" têm sido abundantemente utilizados na formulação de políticas e nos campos profissional e académico, em nome de um "novo paradigma". Diante da utilização panegírica da noção de "envelhecimento ativo", os investigadores sociais críticos deparam-se com uma dificuldade acrescida quando pretendem desconstruir a suposta bondade dessas noções e das políticas que as alimentam. Assim, a complexidade do fenómeno tende a ser descurada, ao mesmo tempo que se acentua o caráter ideológico do designado "envelhecimento ativo". Neste contexto, como sugerem Higgs e Gilleard (2020), o envelhecimento tem sido frequentemente utilizado para descrever uma ideologia global que opera na sociedade em detrimento dos idosos e que, em grande parte, explica a sua marginalidade económica, social e cultural. Contestando tais modelos de envelhecimento orientados para o défice, Pfaller e Schweda (2019) acrescentam que os qualificativos "ativo" e "bem-sucedido", por exemplo, não representam apenas categorias descritivas, mas também visões prescritivas, normativas e avaliativas sobre a velhice, apesar de raramente serem explicitamente reconhecidas e muito menos teoricamente discutidas e justificadas.

Em torno de uma ideologia do sucesso, de raiz meritocrática e performativa, o envelhecimento ativo parece representar, hoje, mais um dever do que um direito (MENDES, 2013). Ademais, como salienta esta autora, a ideologia da obrigação e da responsabilidade associada ao discurso político do envelhecimento ativo gera práticas de exclusão social, na medida em que apenas alguns têm acesso a condições que lhes permitam envelhecer com saúde e "sucesso". Segundo António (2020), a noção de desenvolvimento ativo e saudável foi primeiramente definida pela OMS para enfatizar a responsabilidade da sociedade no seu 
conjunto em relação à qualidade de vida no processo de envelhecimento, enquanto atualmente o paradigma do envelhecimento ativo se concentra, sobretudo, no adiamento da idade da reforma e na redução dos custos com a saúde nos últimos anos de vida, a partir de uma lógica de responsabilização individual. Em relação às "tecnologias do self" incorporadas no imperativo da necessidade de se moverem ou fazerem algo, Marhánková (2011) sustenta que elas participam da produção do discurso do envelhecimento ativo como uma forma de disciplina do corpo, além de ser interiorizado como a forma correta de envelhecimento (MARHÁNKOVÁ, 2011). Gera-se, assim, um discurso homogeneizante que ignora um conjunto de fatores e condições que singularizam não só o envelhecimento como cada pessoa e a sua experiência existencial. António (2020) acrescenta que a par da responsabilização individual pela saúde e, de um modo mais geral, pela forma como se envelhece, assistimos hoje à expansão de um amplo mercado de produtos e serviços anti-envelhecimento que nos permitem argumentar que o ideal de envelhecimento ativo poderá estar ao serviço de uma “indústria da perfeição" (ANTÓNIO, 2020). Estes e outros autores têm dado importantes contributos para a afirmação de uma perspetiva crítica neste campo e é nesse mesmo sentido que destaco, na secção seguinte, a emergência dos estudos intergeracionais.

\section{Perspetivas críticas dos estudos intergeracionais}

No campo dos estudos intergeracionais estes programas e políticas têm sido alvo de várias críticas. Sánchez e Hatton-Yeo (2012) argumentam que, segundo a OMS, manter-se tão autónomo e independente quanto possível, pelo maior tempo possível, torna-se a meta dos programas e políticas de envelhecimento ativo. Na perspetiva destes autores, parece que a OMS está interessada apenas em destacar apenas o lado integrador e não conflituante dos processos intergeracionais: "O objetivo deve ser garantir padrões de vida adequados para as pessoas à medida que envelhecem, reconhecendo e aproveitando as suas habilidades e experiências e encorajando transferências intergeracionais harmoniosas" (WHO, 2002, p. 43). Ao conceber "o envelhecimento ativo em termos de saúde, independência e produtividade dos idosos" (WALKER, 2002, p. 124), a OMS aponta para uma lógica de responsabilização individual, ao mesmo tempo que apresenta uma visão excessivamente otimista e integradora das estruturas sociais e dos seres humanos e uma conceção produtivista do envelhecimento ativo.

Embora seja possível identificar alguns cambiantes nos discursos e estratégias da OMS e da UE, nomeadamente, o uso mais frequente da expressão "envelhecimento ativo e 
saudável", por parte da OMS, e da expressão "políticas de envelhecimento ativo", por parte de instituições da União Europeia, são mais as semelhanças que as diferenças. Estamos perante uma estratégia coerente, por parte das duas organizações, mas que consiste, essencialmente, numa estratégia de natureza individualista, intervencionista e produtivista, com ênfase clara na autonomia e na independência, numa lógica de responsabilização individual vinculada ao discurso da solidariedade intergeracional, mas na realidade pouco propícia à consecução de relações sociais intergeracionais:

\footnotetext{
"Uma abordagem intergeracional para o envelhecimento ativo não consiste em vincular o envelhecimento ativo à solidariedade intergeracional, mas às relações intergeracionais. É através dos encontros entre o envelhecimento, enquanto processo que ocorre ao longo da vida, e as gerações enquanto relações sociais, que a riqueza do envelhecimento intergeracional se torna real". (SÁNCHEZ; HATTON-YEO, 2012, p. 290)
}

Criticando a ideologia individualista, normativista, economicista e produtivista em que se tem transformado o discurso hegemónico do envelhecimento ativo e da solidariedade intergeracional, autores como Hasmanová (2011), Rozanova (2010), Manheimer (2008), Ervik (2006), Walker (2002), Sánchez e Hatton-Yeo (2012) mobilizam argumentos vários, mas em boa parte convergentes:

i. O discurso público sobre o envelhecimento ativo consiste numa estratégia para disciplinar o envelhecimento populacional (HASMANOVÁ, 2011). A ideia que é difundida é de que cada pessoa, estando constantemente ativa, pode influenciar as condições do seu próprio envelhecimento. A atividade é "apresentada como um caminho para um envelhecimento saudável e feliz, e como parte integral da responsabilidade dos idosos em relação a si mesmos" (HASMANOVÁ, 2011, p. 13). A estratégia do envelhecimento ativo revela, assim, a mudança da responsabilidade coletiva para a responsabilidade individual;

ii. Os quadros normativos das duas organizações, além de focados no indivíduo, tendem a dizer-lhe o que deve fazer para envelhecer bem (ERVIK, 2006). A ênfase na atividade ignora que a dependência é um conceito relacional, não podendo ser vista na perspetiva da vulnerabilidade e do deficit do indivíduo;

iii. As abordagens individualistas e produtivistas subjacentes ao discurso do envelhecimento ativo e da solidariedade intergeracional põem em risco a própria 
solidariedade intergeracional, uma vez que ignoram e ameaçam a natureza relacional que está no cerne das práticas intergeracionais (MANHEIMER, 2008);

iv. Os media acentuam a ideia de que o envelhecimento ativo é um envelhecimento bem-sucedido, "estigmatizando alguns adultos mais velhos que podem não ter a capacidade de cumprir as expectativas delineadas pelo discurso do envelhecimento de sucesso" (ROZANOVA, 2010: 125). A responsabilidade pelo envelhecimento malsucedido é assacada ao indivíduo que, supostamente, não soube manter-se suficientemente ativo para envelhecer com sucesso. Embora o indivíduo não viva à margem da sociedade e dos vários constrangimentos estruturais - a economia de mercado, as organizações do trabalho, os sistemas de saúde, etc. - o discurso do envelhecimento de sucesso atribui, direta ou indiretamente, a culpa ao indivíduo, fazendo-o sentir-se responsável pelo que é percebido como um fracasso pessoal;

v. O envelhecimento ativo é intergeracional, pois diz respeito a todos os nossos futuros e não apenas às pessoas mais velhas (WALKER, 2002). É necessário que o envelhecimento ativo se traduza numa estratégia coerente, capaz de responder aos desafios do envelhecimento da população, e não num mero slogan. Para Walker (2002), a solidariedade intergeracional deve fazer parte dessa estratégia desde que signifique, também, justiça entre as gerações.

Sánchez e Hatton-Yeo (2012, p. 287-290) dão um importante contributo para a teorização das questões intergeracionais no quadro das políticas, investigação e práticas do envelhecimento ativo, fornecendo cinco "axiomas inter-relacionados":

i. Os seres humanos têm diferentes experiências, pensamentos e desejos sobre o envelhecimento, pelo que o qualificativo "ativo", no que tange ao envelhecimento ativo, não consiste na mera realização de atividades específicas, mas sobretudo na consciência e na disposição das pessoas para prestarem atenção ao modo como se pode envelhecer melhor;

ii. Sendo o envelhecimento um fenómeno complexo e multidimensional, devemos evitar discussões reducionistas sobre o envelhecimento ativo, as quais são impulsionadas por preocupações económicas que não procuram compreender adequadamente as experiências de envelhecimento das pessoas e as inter-relações complexas que existem nos seus ambientes e comunidades; 
iii. As políticas de envelhecimento ativo devem concentrar-se em tornar as relações intergeracionais o mais fáceis possível para pessoas de todas as idades. São as relações intergeracionais que devem estar na vanguarda dos princípios do envelhecimento ativo e não a solidariedade intergeracional proclamada pela OMS e a EU. Como os relacionamentos intergeracionais são ambivalentes, não devemos esforçar-nos para os tornar apenas fontes de solidariedade, mas principalmente oportunidades de "estar com" e "estar juntos" de forma intergeracional;

iv. O envelhecimento ativo não diz respeito apenas ao envelhecimento das pessoas mais velhas. Para a OMS e a EU o âmbito etário do envelhecimento ativo restringe-se às faixas de 60 anos ou mais e 55 anos ou mais, o que é contraditório com a assunção da solidariedade intergeracional como um princípio de envelhecimento ativo. É essencial que o envelhecimento ativo seja uma preocupação de todos, sendo por isso necessário adotar uma lente intergeracional inclusiva, ou seja, que todos devemos incluir qualquer geração e qualquer idade;

v. Como os relacionamentos intergeracionais são ambivalentes, o envelhecimento ativo também pode ser ambivalente. A vida e o envelhecimento ocorrem dentro de uma estrutura complexa e dinâmica de relacionamentos com os outros, no entanto, as abordagens prescritivas da OMS e da UE fornecem uma visão simplista do mundo em que vivemos. Não reconhecendo a complexidade das relações intergeracionais, essas abordagens prescritivas são incapazes de ver e valorizar a importância de uma abordagem interdependente e relacional.

Nem todas as práticas intergeracionais obedecem cegamente aos modelos normativos e prescritivos da OMS e da EU, mas a lente individualista, produtivista e intervencionista adotada por estes dois organismos tende a reduzir o espectro muito amplo das relações intergeracionais. A alteração de atitudes idadistas passa por uma mudança ideológica de grande espetro e por mudanças políticas e organizacionais em áreas como a educação, a saúde, o trabalho, a segurança social, etc., sem esquecer a importância da formação e conscientização dos profissionais para o desenvolvimento de práticas intergeracionais antiidadistas. Considerando que o fenómeno do idadismo tem raízes culturais profundas, é necessário apostar em ações potencialmente transformadoras das representações que os 
indivíduos têm acerca dos vários grupos etários e na mudança de práticas ao nível das relações e interações sociais cotidianas.

\section{A educação intergeracional como pedagogia crítica}

A intergeracionalidade tem hoje uma visibilidade social, política e mediática que não tinha há algumas décadas, mas sempre houve contactos e relações intergeracionais, pois "todo o ser humano é intergeracional":

\footnotetext{
"Somos e existimos porque, imediatamente após o nascimento, começamos a cruzar-nos com outras pessoas que, com um percurso mais longo nos seus próprios cursos vitais, apoiam a nossa existência: pensamos em pais, professores e outras pessoas adultas - parentes ou não - de quem inevitavelmente dependemos para prosseguir nas nossas fases iniciais da vida. Nesses momentos, ninguém duvidaria da indispensabilidade do contacto intergeracional". (SÁNCHEZ; KAPLAN; SÁEZ, 2010, p. 26).
}

Uma dimensão fundamental das relações intergeracionais é a dimensão educativa, não ignorando que ela é indissociável de outras dimensões já referidas: social, económica, política, cultural, entre outras. No entanto, é necessário, em primeiro lugar, não restringir o conceito de educação à dimensão escolar, desde logo porque é inerente à educação intergeracional o questionamento e a tentativa de superação da tendência crescente de institucionalização, curricularização e etarização da educação, com efeitos em escolas e jardins de infância, mas também em lares e centros de dia. Em segundo lugar, não usamos o conceito de educação intergeracional em sentido equivalente ao de aprendizagem intergeracional. Ainda que frequentemente os dois conceitos sejam usados de maneira quase indiscriminada, consideramos pertinente estabelecer uma distinção, entre outras razões porque o conceito de aprendizagem tem sido instrumentado por instituições da EU no âmbito das "políticas de aprendizagem ao longo da vida" (LIMA, 2012) numa lógica similar à das "políticas de envelhecimento ativo": uma lógica que, como referimos anteriormente, é predominantemente individualista, produtivista, economicista e normativista. Em terceiro lugar, a intergeracionalidade não pode circunscrever-se a atividades pontuais, realizadas, sobretudo, em datas festivas, como o Natal, e noutros dias comemorativos, por exemplo o Dia do Idoso. Finalmente, a educação intergeracional não pode restringir-se ao contacto entre gerações dos polos extremos da composição etária de uma determinada sociedade ou comunidade: crianças e idosos. Frequentemente, os contactos entre essas duas gerações, além de não terem um caráter sistemático, ocorrem em atividades de creches, jardins-de-infância e 
escolas, e de lares e centros de dia, reproduzindo, muitas vezes, o modelo escolar, material e simbolicamente. A institucionalização das crianças e dos idosos não é questionada por este tipo de práticas intergeracionais que não envolvem todas as gerações nem se abrem aos vários espaços e recursos da comunidade e da cidade.

É certo que há instituições educativas que desenvolvem atividades e projetos intergeracionais, frequentemente com benefícios muito positivos para os participantes. $\mathrm{O}$ que não podemos ignorar é que a "forma escolar de socialização e aprendizagem" (VINCENT, 1994) consiste numa forma específica de relações sociais historicamente fundada na homogeneização etária, através da adoção da "classe" como estrutura nuclear de organização da escola (BARROSO, 1995). Por isso, a educação intergeracional não pode deixar de questionar a instituição escolar como "produto da sociedade moderna e, consequentemente, como parte do arcabouço institucional e do aparato simbólico que lhe dá sustentação" (XAVIER; CHAVES, 2018). Em grande medida, o paradigma escolar é responsável pela perpetuação da segmentação etária das relações sociais de sociabilidade e de aprendizagem e, como tal, o seu questionamento é inerente à superação do mesmo. Porém, mais do que estabelecer fronteiras entre pedagogias escolares e sociais, é necessário, como argumenta Gadotti (2012), distinguir as pedagogias que reclamam para si um estatuto de ciência neutra, das pedagogias críticas que afirmam os seus princípios e valores e não escondem a politicidade da educação - da educação popular, da educação social e da educação comunitária. Enquanto as primeiras tendem a ocultar os interesses hegemónicos da sociedade e conceções de educação, por vezes, autoritárias e domesticadoras, as segundas têm em comum um campo de significação pedagógica, ou seja, o campo democrático e popular (GADOTTI, 2012). É, pois, na pedagogia crítica (FREIRE, 1967, 1975; GIROUX, 2010; MCLAREN, 2010, 2020), da qual Paulo Freire é um dos principais pioneiros, que a educação intergeracional pode ancorar-se. Deste modo, poderá contribuir para a desescolarização da educação e a desinstitucionalização das pessoas idosas e também de crianças e jovens; promover a cidadania intergeracional; e contribuir, através da experiência participativa e convivial, para um “novo espaço público da educação" (NÓVOA, 2002, p. 1).

Como salientam Sánchez, Kaplan e Sáez (2010), os programas intergeracionais são desenvolvidos de forma muito diversa e têm, na maioria dos casos, uma base conceitual e teórica limitada. Por isso, estes autores defendem que uma tarefa prioritária relativa à conceção e ao desenvolvimento de programas intergeracionais consiste em construir bases 
teóricas sólidas e coerentes, especialmente no contexto de uma prática multi e interdisciplinar. Num trabalho de síntese, Mannion (2016) analisa um conjunto de trabalhos teóricos e empíricos de diferentes áreas e identifica três orientações emergentes e que considera necessárias para a sustentação teórica, política e prática da educação intergeracional:

i. a necessidade de mudar de olhar, do modelo unigeracional baseado em inputs e outputs, para o modo como o processo de aprendizagem intergeracional é relacionalmente e reciprocamente experienciado pelos participantes;

ii. a necessidade de direcionar o foco da aprendizagem intrafamiliar para um foco que ilumine os diversos lugares extrafamiliares de encontros intergeracionais, que têm um potencial ainda pouco explorado como contextos de aprendizagem intergeracional;

iii. a necessidade de ampliar os propósitos dos programas intergeracionais, de modo a que incluam não só melhores relações entre as gerações, mas também a melhoria do bem-estar ecossocial. De acordo com este autor, as três mudanças sugerem, em conjunto, a necessidade de uma compreensão localmente responsiva da educação intergeracional.

Existem vários tipos de programas intergeracionais que mostram, justamente, a pluralidade e a heterogeneidade acima referidas: "escolas comunitárias intergeracionais" (WHITEHOUSE; BENDEZU; FALLCREEKM; WHITEHOUSE, 2000), “comunidades de aprendizagem intergeracional" (NEIKRUG, 2005), "cidades habitáveis para todas as idades" (VAN VLIET, 2009), outros programas focados no ambiente e na saúde (KAPLAN; LIU; STEINIG, 2005) e, especificamente, os que utilizam a literatura infantil (LARKIN; WILSON; FREER, 2013; MCGUIRE, 2016) como prática educativa transformadora diante do poder discriminatório do idadismo. Há autores que elaboram categorizações ou tipologias para distinguir uns programas intergeracionais de outros, evidenciando aspetos como a área de interesse, os serviços prestados, as atividades realizadas, as entidades promotoras, os profissionais e voluntários envolvidos, os benefícios para os participantes, etc. Por exemplo, utilizando como critério o serviço prestado, podemos distinguir três tipos:

i) programas em que adultos atendem crianças e / ou jovens (como tutores, mentores, precetores e amigos, cuidadores, etc.); 
ii) programas em que crianças e / ou jovens prestam serviços a adultos (visitamnos, acompanham-nos, supervisionam algumas tarefas realizadas por essas pessoas, etc.);

iii) programas em que adultos colaboram com crianças e / ou jovens para servir a comunidade (por exemplo, em projetos de desenvolvimento ambiental ou direcionados para problemas sociais). (SÁNCHEZ; DÍAZ, 2005).

Embora os diferentes critérios sejam pertinentes, alguns não enfatizam suficientemente o grau de engajamento dos participantes nos programas e atividades intergeracionais. A ênfase colocada no serviço prestado ou mesmo nos benefícios de um determinado programa intergeracional parece conferir-lhe um caráter unidirecional - uma ação exercida por "promotores" dirigida a "destinatários", "utentes" ou "públicos-alvo" - e não um carácter multidimensional que implica a interação e a implicação dos participantes.

A educação intergeracional pode desenvolver-se nos mais variados espaços, intra e extrafamiliares, contribuindo tanto para o fortalecimento das sociabilidades, através da criação de oportunidades contínuas de contato, intimidade e convivência, como para o reforço do espaço público da educação e da cidadania intergeracional. Por exemplo, as associações e outras organizações da sociedade civil são potencialmente fecundas para o desenvolvimento da educação intergeracional, não pela via da aprendizagem de conteúdos curriculares, mas do alargamento do campo de experiências e linguagens dos participantes. Neste sentido, é essencialmente a ação coletiva e as inerentes situações e condições de participação social, política e cidadã que consubstanciam a dimensão educativa crítica das práticas e das relações intergeracionais.

\section{Conclusão}

As atitudes e práticas idadistas representam uma violação de direitos: direitos civis e políticos, mas também económicos, sociais e culturais. Nesse sentido, é fundamental o (re)conhecimento e a promoção dos "Direitos da Criança", do "Estatuto da Criança e do Adolescente", do "Estatuto da Juventude", do "Estatuto do Idoso", entre outras declarações, convenções e ordenamentos jurídicos de âmbito nacional ou internacional, mas eles espelham simultaneamente o quanto está enraizada a homogeneização e a segmentação etária nas mais diversas culturas e sociedades. Segundo Palmore, Branch e Harris (2005), diferentemente do 
racismo, do sexismo e do heterossexismo, cujas vítimas de discriminação pertencem a grupos específicos, todos nos tornamos vulneráveis ao idadismo, bastando viver o tempo suficiente.

A necessidade de reflexão e análise críticas é particularmente evidente quando lidamos com situações frequentemente invisíveis, que tendem a escapar à vigilância crítica. Basta notar, por exemplo, que este próprio texto contém inúmeras hesitações quanto à terminologia a usar em relação às pessoas comummente designadas "idosas": seniores, pessoas maiores, pessoas idosas, pessoas mais velhas, etc. Embora a expressão "menores de idade" não seja particularmente feliz, poderíamos usar, em relação às pessoas idosas, a expressão "pessoas de maior idade", não como sinónimo do termo maioridade, mas no sentido de "idade maior". Contudo, num campo em que abundam os eufemismos, em que os mitos, as crenças e os estereótipos que estão na base do preconceito e da discriminação idadista se manifestam de formas subterrâneas, inconscientes ou difusas, o esforço de desocultação não é apenas uma exigência científica, mas também social, política e ética. A investigação nunca é neutra e, neste caso, ela não pode deixar de ser comprometida, colocando-se no plano da cidadania e numa perspetiva de investigação cidadã. A reflexão e a análise críticas têm, pois, um papel crucial no esforço de teorização que é necessário fazer no campo emergente dos estudos intergeracionais. Embora as estratégias de combate ao idadismo tenham particularidades, elas devem inserir-se na estratégia mais ampla de defesa e promoção dos Direitos Humanos.

Numa abordagem da educação intergeracional crítica e cidadã, tanto o idadismo, como o racismo, o sexismo e outros fundamentalismos não podem ser tolerados numa sociedade que se diz igualitária, democrática e inclusiva. Concebendo a educação intergeracional como promotora e produtora de cidadania, uma abordagem focada nos direitos diz respeito aos cidadãos e cidadãs, sem qualquer tipo de discriminação ou exclusão. Convém esclarecer que as crianças não são cidadãs em devir, são cidadãs no presente, nos seus mundos sociais e culturais. Por sua vez, as pessoas idosas não deixam de ser cidadãs quando institucionalizadas ou, de uma maneira geral, quando não se mostram capazes de se manterem independentes e autónomas, sobretudo na ótica do designado desenvolvimento ativo, saudável e "bemsucedido". Contra o discurso político dito estratégico, mas aparentemente anódino, da "solidariedade entre gerações", proclamado por organização internacionais como a OMS e a União Europeia, defendo uma educação intergeracional crítica promotora e produtora de cidadania intergeracional, capaz de alargar e fortalecer o espaço público da educação, pela via da experiência democrática e convivial. São vastas as possibilidades transformadoras de uma educação intergeracional crítica e cidadã, na justa medida em que possam contribuir para a 
erradicação de todas as formas de discriminação e para a inclusão de todas as pessoas, respeitando, com a mesma dignidade, o direito à igualdade e à diferença.

\section{Referências}

ABRAMS, Dominic; RUSSELL, Pascal; VAUCLAIR, Christin-Melanie; SWIFT, Hannah. Ageism in Europe. Findings from the European Social Survey. A Report from EURAGE (European Research Group on Attitudes to Age) commissioned by Age UK. Age UK, 2011.

ANTÓNIO, Manuel. Envelhecimento ativo e a indústria da perfeição. Saúde Soc. São Paulo, v.29, n.1, e190967, p. 1-11, 2020.

BARROSO, João. Os Liceus. Organização Pedagógica e Administração (1836-1960). Lisboa: Fundação Calouste Gulbenkian, 1995.

BENGTSON, Vern L.; OYAMA, Petrice S. Intergenerational solidarity: strengthening economic and social ties. Expert group meeting: background paper. New York: United Nations Headquarters, 2007.

BUTLER, Robert, N. Ageism: another form of bigotry. The Gerontologist, v. 9, n. 4, Part 1), p. 243-246, 1969.

COLEMAN, Peter G; O’HANLON, Ann. Ageing \& development. New York: Arnold, 2004.

COMISSÃO EUROPEIA, Livro verde sobre o envelhecimento. Promover a responsabilidade e a solidariedade entre gerações, 2021. Disponível em:

https://ec.europa.eu/info/sites/info/files/com_2021_50_f1_green_paper_pt.pdf, Acesso em 15 de mar. 2021.

COUNCIL OF THE EUROPEAN UNION. Council conclusions on active ageing, 2010. Disponível em:

https://www.consilium.europa.eu/uedocs/cms_Data/docs/pressdata/en/lsa/114968.pdf, Acesso em 24 out. 2019.

DAATLAND, Sven O.; LOWENSTEIN, Ariela. Intergenerational solidarity and the familywelfare state balance, European Journal of Ageing, v. 2, n. 3, p. 174-182, 2005.

ERVIK, Rune. Pitfalls and possibilities of active ageing conceptualisations and policies. Paper presented at the Conference Towards a Multiage Society: The cultural dimension of age policies, Brussels, 29-30, November. 2006. Disponível em https://docplayer.net/39970556Pitfalls-and-possibilities-of-active-ageing-conceptualisations-and-policies.html, Acesso em: 20 out. 2020.

EUROPEAN PARLIAMENT; COUNCIL OF THE EUROPEAN UNION. Decision n.940/2011/EU of the European Parliament and of the council of 14 September 2011 on the European Year for Active Ageing and Solidarity between Generations, 2011. 
EUROPEAN PARLIEMENT. Demographic outlook for the European Union 2020, European Union, 2020. Disponível em:

https://www.europarl.europa.eu/RegData/etudes/STUD/2020/646181/EPRS_STU(2020)6461 81_EN.pdf, Acesso em: 31 jan. 2021.

EUROPEAN UNION. Active ageing and solidarity between generations A statistical portrait of the European Union 2012, Luxembourg: European Union, 2011.

FREIRE, Paulo. A educação como prática de liberdade. Rio de Janeiro: Paz e Terra, 1967 (1ª ed.; $19^{\mathrm{a}}$ ed. 1989).

FREIRE, Paulo. Pedagogia do Oprimido. Porto: Afrontamento, 1975 (1ª ed. 1970, Nova Iorque; manuscrito em português de 1968; $1^{\mathrm{a}}$ ed. em português 1974).

GADOTTI, Moacir. Educação Popular, Educação Social, Educação Comunitária: conceitos e práticas diversas, cimentadas por uma causa comum, Revista Diálogos: pesquisa em extensão universitária. IV Congresso Internacional de Pedagogia Social: domínio epistemológico. Brasília, v.18, n.1, p. 10-32, dez, 2012.

GIROUX, Henry A. Rethinking Education as the Practice of Freedom: Paulo Freire and the promise of critical pedagogy. Policy Futures in Education, v.8, n.6, p. 715-721, 2010.

HASMANOVÁ, J. Leisure in old age: Disciplinary practices surrounding the discourse of active ageing. International Journal of Ageing and Later Life, v. 6, n. 1, p. 5-32, 2011.

HIGGS, Paul; GILLEARD, Chris. The ideology of ageism versus the social imaginary of the fourth age: Two differing approaches to the negative contexts of old age. Ageing and Society, v. 40, n. 8, p. 1617-1630, 2020.

KAPLAN, Matthew; LIU, Shih-Tsen; STEINIG, Sheri. Intergenerational approaches for environmental education and action. Sustainable Communities Review, v. 8, n. 1, p. 54-74, 2005.

KOHLI, Martin. Social organization and subjective construction of the life course. In A. B. SORENSEN, F. E. WEINER; L. R. SHERROD (Eds.). Human development and the life cycle. Hillsdale, NJ: Erlbaum, 1988, p. 271-292.

LARKIN, Elizabeth; WILSON, G. Patricia; FREER, Maria. Images of Old: Teaching About Aging Through Children's Literature. Journal of Intergenerational Relationships, v. 11, n. 1, p. 4-17, 2013.

LIMA, Licínio C. Aprender para ganhar, conhecer para competir: sobre a subordinação da educação na "sociedade da aprendizagem”. São Paulo: Cortez, 2012.

LLOYD, Liz et al. Look after yourself: active ageing, individual responsibility and the decline of social work with older people in the UK, European Journal of Social Work, v.17, n.3, p. 322-335, 2014. 
MANHEIMER, Ronald J. The paradox of beneficial retirement: A journey into the vortex of nothingness. Journal of Aging, Humanities, and the Arts, v. 2, n. 2, p. 84-98, 2008.

MANNION, Greg. Intergenerational Education and Learning: We are in a new place. In SKELTON, T., PUNCH, S.; VANDERBECK, R. M. (Eds.). Families, Intergenerationality and Peer-Group Relations.London: Springer, 2016.

MARHÁNKOVÁ, Jaroslava H. Leisure in old age: disciplinary practices surrounding the discourse of active ageing. International Journal of Ageing and Later Life, 2011, v.6 n.1, p. 5$32,2011$.

MARQUES, Sibila. Discriminação da Terceira Idade. Lisboa: Fundação Francisco Manuel dos Santos, 2011.

MCGUIRE, Sandra L. Early Children's Literature and Aging. Creative Education, n. 7, p. 2604-2612, 2016.

MCLAREN, Peter (2010). Revolutionary critical pedagogy. Inter Actions: UCLA Journal of Education and Information Studies, n.7, p. 1-11.

MCLAREN, Peter (2020) The future of critical pedagogy. Educational Philosophy and Theory, v.52, n.12, p.1243-1248, 2020.

MENDES, Felismina R. Active ageing: A right or a duty? Health Sociology Review, v.22, n.2, p. 174-185, 2013.

NEIKRUG, Shimshon. Creating an Intergenerational Learning Community for the Study of Elder Abuse. Journal of Elder Abuse \& Neglect, v. 16, n. 2, p. 33-49, 2005.

NÓVOA, António. O espaço público da educação: Imagens, narrativas e dilemas. In A. Nóvoa (Dir.). Espaços de Educação, Tempos de Formação. Lisboa: Fundação Calouste Gulbenkian, 2002, p. 237-263.

PALMORE, Erdman B.; BRANCH, Laurence; HARRIS, Diane (Eds.). Encyclopedia of ageism. New York: The Haworth Press, 2005.

PALMORE, Erdman B.; WHITTINGTON, Frank; KUNKEL, Suzanne (Eds.). International handbook on aging. Santa Barbara, CA: Praeger, 2009.

PFALLER, Larissa; SCHWEDA, Mark. Excluded from the Good Life? An Ethical Approach to Conceptions of Active Ageing. Social Inclusion, v.7, n.3, p. 44-53, 2019.

PORGUGAL-PORDATA. Retrato dos Homens e das Mulheres. Lisboa: Fundação Francisco Manuel dos Santos, 2018.

PORTUGAL. Estimativas de População Residente em Portugal 2019. Lisboa: Instituto Nacional de Estatística (INE). Disponível em 
https://ine.pt/xportal/xmain?xpid=INE\&xpgid=ine_destaques\&DESTAQUESdest_boui=4144 36913\&DESTAQUESmodo=2, Acesso em: 14 dez. 2020.

ROZANOVA, Julia. Discourse of successful aging in The Globe \& Mail: Insights from critical gerontology. Journal of Aging Studies, n. 24, p. 213-222, 2010.

SÁNCHEZ, Mariano; DÍAZ, Pilar. Los programas intergeneracionales. In: PINAZO, S.; SÁNCHEZ, M. (Dir.). Gerontología. Actualización, innovación y propuestas. Madrid: Pearson Prentice Hall, 2005, p. 393 - 430.

SÁNCHEZ, Mariano; HATTON-YEO, Alan. Active Ageing and Intergenerational Solidarity in Europe: A Conceptual Reappraisal from a Critical Perspective. Journal of Intergenerational Relationships, v.10 n.3, p. 276-293, 2012.

SÁNCHEZ, Mariano; KAPLAN, Matthew; SÁEZ. Juan. Programas intergeneracionales. Guía introductoria. Madrid: Ministerio de Sanidad y Política Social, Instituto de Mayores y Servicios Sociales, 2010.

UNITED NATIONS, Department of Economic and Social Affairs, Population Division. World Population Ageing 2020 Highlights: Living arrangements of older persons (ST/ESA/SER.A/451). New York: United Nations, 2020.

VAN VLIET, Willem. Creating livable cities for all ages: Intergenerational strategies and initiatives. Working Paper CYE-WP1-2009. Children, Youth and Environments Center, University of Colorado, 2009.

VINCENT, Guy (Ed.). L'éducation prisonnière de la forme scolaire? Scolarisation et socialisation dans les sociétés industrielles. Lyon: Presses Universitaires de Lyon, 1994.

WALKER, Alan. A strategy for active ageing. International Social Security Review, v. 55, n. 1, p. 121-139, 2002.

WHITEHOUSE, Peter J.; BENDEZU, Eve; FALLCREEK, Stephanie; WHITEHOUSE, Catherine. Intergenerational community schools: a new practice for a new time, Educational Gerontology, n. 26, p. 761-770, 2000.

WHO. Active ageing: A policy framework, Geneva: World Health Organization, 2002. Disponível em: https://www.who.int/ageing/publications/active_ageing/en/, Acesso em: 23 set. 2019.

WHO. Decade of Healthy Ageing - Baseline Report, 2020. World Health Organization, 2020. Disponível em: https://cdn.who.int/media/docs/default-source/mca-documents/decade-ofhealthy-ageing-baseline-report_06012021.pdf?sfvrsn=eaad1517_1\&download=true. Acesso em 15 mar. 2021.

WHO. Global strategy and action plan on ageing and health, World Health Organization 2017. Disponível em: https://www.who.int/ageing/WHO-GSAP-2017.pdf?ua=1, Acesso em: 10 fev. 2021. 
WHO. Strategy and action plan for healthy ageing in Europe, 2012-2020. World Health Organization, 2012. Disponível em:

https://www.euro.who.int/_data/assets/pdf_file/0008/175544/RC62wd10Rev1-Eng.pdf. Acesso em: 30 set. 2019.

XAVIER, Libânia N.; CHAVES, Miriam W. A invenção da Escola pública e seus desdobramentos no Brasil: entre o ideal de modernidade e os problemas contemporâneos, Historia Caribe, v. XIII, n. 33, jul./dez., p. 253-280, 2018. 